\title{
Transforming practice, transforming practitioners: reflections on the TQFE in Scotland
}

Dr Yvonne Bain, Dr Kevin Brosnan, Dr Aileen McGuigan

Dr Yvonne Bain, School of Education and Social Work, University of Dundee, Dundee, Scotland

Dr Kevin Brosnan, Faculty of Social Science, University of Stirling, Stirling Scotland

Dr Aileen McGuigan, School of Education and Social Work, University of Dundee, Dundee, Scotland

\section{Correspondence:}

Dr Kevin Brosnan

Programme Director: TQFE

E-mail: k.d.r.brosnan@stir.ac.uk

Faculty of Social Sciences

University of Stirling, Stirling, FK9 4LA 


\section{Short biographical details for each author}

Dr Yvonne Bain was the programme director for the TQFE programmes at the University of Aberdeen. She has presented at international conferences on the professional learning of teachers and on online learning. Yvonne has had many years of experience of teaching in different contexts and in online environments.

Dr Kevin Brosnan is programme director of the TQFE courses at the University of Stirling. His research interests focus on the use of networked technologies in the support of professional learning and continuing professional development. He gained his $\mathrm{PhD}$ in 2007 from the University of Lancaster.

Dr Aileen McGuigan led the Teaching Qualification in Further Education programme between 2010 and 2016 at the University of Dundee, where the programme is delivered online to some 150 participants annually. Aileen's research interests are in the fields of design for online learning and social media tools in learning contexts; she has published various articles and presented at national and international conferences on these topics. 


\title{
Transforming practice, transforming practitioners: reflections on the TQFE in Scotland
}

\begin{abstract}
This study offers reflections on the TQFE in Scotland as an example of the transformative professional learning model as identified by Kennedy (2005). The focus of this study is the professional learning of lecturers in Scotland's colleges. Informed by wider considerations of teacher education more broadly, it will be of particular interest to those supporting a transformative model of professional learning in a variety of educational contexts. The research was undertaken as a collaborative initiative between each of the three Universities which offer the TQFE in Scotland. Qualitative data are drawn from former TQFE participants and college mentors, and thematic analysis used to gain further insight from participant interviews. Findings highlight the transformative nature of the TQFE with an impact that is beyond the currency of the TQFE programme duration. The provision of transformative professional learning opportunities is now imperative given various pressures and tensions around the development of educators more generally and within contemporary Scottish Further Education in particular. Such pressures and tensions include: the varied demands within the Professional Standards for Lecturers in Scotland's Colleges (Scottish
\end{abstract} Government, 2012), and the need for professional learning for college lecturers to go beyond a competency or tool-kit based approach and to be sustainable.

Keywords: TQFE, Further Education, professional development, transformative learning, professional identity

Subject classification codes: include these here if the journal requires them 


\section{Background / introduction}

The Teaching Qualification in Further Education (TQFE) in Scotland has professional recognition by the General Teaching Council for Scotland (GTCS) and has academic accreditation by the three Universities in Scotland which provide the TQFE: the University of Aberdeen, the University of Dundee, and the University of Stirling. The qualification is underpinned by guidelines for indicative content and professional standards which were developed through Scotland's Colleges Professional Learning and Development Forum, and approved by the Scottish Government (see Scottish Government 2012, for the current professional standards).

Most Lecturers in Scotland's colleges undertake the TQFE whilst in-service. The lecturers are often appointed to the role on the basis of their vocational and/or professional and academic expertise and, once in post, they are then encouraged by the college employer to undertake the teaching qualification as an in-service, work-based qualification (although some do gain their qualification as a pre-service award as available through Stirling University). It is not mandatory to have a TQFE to teach in Scotland's colleges, but colleges are strongly encouraged (by the Scottish Government) to ensure that permanent lecturing staff gain a teaching qualification within the first two or three years of being appointed. The TQFE is recognised as jointly lecturer 'education' and 'training' in the subtitle of the Professional Standards document - 'Initial teacher training/education standards for lecturers in Scotland's colleges' (Scottish Government 2012) - that is, pertaining to theory and knowledge (education) as well as skills (training). The position of the TQFE in Scotland is similar to initial teacher education qualifications for college lecturers in the rest of the UK but (unlike the rest of the UK) it is only available as a university course. 
In April 2010 the Scottish Government published the 'Report of the 2009 Candidate Survey of the Teaching Qualification (Further Education) (TQFE)' (Scottish Government 2010). The 2009 survey focused on a small number of themes which had previously been examined in a 2001-02 survey. Key aspects examined in the 2010 report were the extent to which programmes addressed the professional standards (Scottish Executive 2006) and the effect the TQFE was having on candidates' subsequent teaching practice.

Key findings from the 2009 survey included:

- $89 \%$ of respondents recommended their TQFE programme to others, comparing positively with the $76 \%$ figure from the original candidate survey conducted in 2001-02.

- The satisfaction rate (which excludes neutral responses) remained above $70 \%$ for all questions and in many instances was well over $80 \%$, indicating that, overall, candidates are very positive about their TQFE experience.

- All questions relating to how well the TQFE programmes addressed the Professional Standards for Lecturers received an above $80 \%$ satisfaction rate.

- Results indicate that the TQFE is having a positive effect on candidates' lecturing practice.

- The strength of feeling expressed by candidates in relation to their university and college mentors highlights the importance of these roles in providing support and motivation to candidates, enhancing the effectiveness of TQFE programmes generally. 
It is now seven years since that survey was completed. In line with HEI quality assurance processes each of the TQFE programmes gathers internal evaluative data which continue to affirm the findings of the 2009 survey, with course participants and other stakeholders moreover regularly highlighting the transformative nature of the TQFE experience.

The three universities which currently offer the TQFE (Aberdeen, Dundee, and Stirling) sought to explore further the perceptions of TQFE as a transformative professional learning experience. In the current study, the authors draw from a wide perspective of professional practice to examine the participants' perceptions of their experience of TQFE and the influence of TQFE on their subsequent professional practice. Reflections on the results are presented using Kennedy's model of transformative professional learning as an analytical framework.

Data for this study was gathered via an initial questionnaire survey and followed up with a set of qualitative interviews conducted with ex-TQFE students. The interviewees were drawn from colleges across Scotland - including institutions from the Highlands and Islands to the central belt of Scotland. Thematic analysis was used to identify key themes cutting across a range of responses with each theme being exemplified with a series of quotes taken from participant interview transcripts.

\section{Transformative professional learning and TQFE}

In an article considering Continuing Professional Development (CPD) for teachers, Kennedy (2005) outlines nine different models of CPD and although written with school teachers in mind, her findings are also pertinent in the Further Education (FE) 
context, where the same models of CPD can be identified. Those models are intended together to form a framework 'through which CPD policies and practice can be analysed and compared'(Kennedy, 2005, 247) and may be considered as a continuum, with 'transmission' models at one end, 'transitional' in the middle and 'transformative' models at the other. The transmission models are those primarily to do with 'training', such as the highly technocratic 'training model' - where an expert delivers to the passive teacher, the 'deficit model' - designed to remedy a specific weakness; transitional models include the 'coaching/mentoring model' amongst others. At the opposite end of the spectrum are models which are primarily about theory and knowledge creation or 'education' - such as the 'action research model' and the 'transformative model', which 'involves the combination of a number of processes and conditions - aspects of which are drawn from other models outlined' (Kennedy 2005, 246). Kennedy recognises that more than a model of CPD in its own right, the so-called 'transformative model' is about the transformation of practice as a result of this combination of processes and conditions.

Models of professionalism and teacher education are further considered by Beauchamp et al. (2016) who cite the literature review of teacher education undertaken by Menter et al. (2010) who note four models of teacher professionalism as:

- The effective teacher - as measured against standards and competencies

- The reflective teacher - with teachers making decisions based on informed reflections of practice

- The enquiring teacher - with teachers and lecturers in schools and colleges engaging in action research which often involves collaborative partnerships with universities 
- The transformative teacher - which has an expectation of the teacher as an "activist" whose practice encompasses social change and enables young people to contribute to addressing societal inequalities.

Ranging from the 'trained' teacher to the 'educated' one, who is reflective, enquiring and ultimately transformative, these models of professionalism resonate strongly with Kennedy's CPD framework. The Professional Standards for Lecturers in Scotland's Colleges (Scottish Government 2012) might suggest that the model of professionalism for college lecturers is to create 'effective practitioners' in a technocratic sense. However, within these standards are clear indicators that lecturers are to be: 'reflective, including being able to critically evaluate influences on education (political, social, and economic); to have a critical understanding of theories of learning and to 'review evidence-based practice and pedagogical research' (Scottish Government 2012,13). Within the standards there is an expectation of lecturers engaging in ongoing development of practice but this does not go as far as the transformative model of professionalism such as lecturers being activist in nature.

Professional learning for educators needs to be supportive of a transformative model and to go beyond that of the "effective teacher" model (Beauchamp et al, 2016 citing Menter et al, 2010). A transformative professional development model at the very least requires the practitioners to be able to engage in systematic processes for reflection, to inform practice with reference to research, policy, and practice and to recognise the complexities of professional practice set against the ever changing political, social, and economic climates. The authors would argue that the TQFE model of professional learning is transformative. This echoes Tripp's (1993) assertions: 
'Good teachers use good techniques and routines, but techniques and routines alone do not produce good teaching. The real art of teaching lies in teachers' professional judgement because in teaching there is seldom one "right answer". This combination of experience, flexibility, informed opinion and constant self-monitoring is not easy to acquire.' Professional learning requires an in-depth exploration of practice supported by critical reflection.

A key aspect of a transformative professional learning model is to be critically reflective. This idea of being reflective in practice builds from the early work of Dewey who advocated reflection as a key process for learning in which reflection "is turning a topic over in various aspects and in various lights so that nothing significant about it shall be overlooked - almost as one might turn a stone over to see what its hidden side is like or what is covered by it" (Dewey 1910, 172). The reflection and enquiry approach of Dewey was influential in Schön's (1983) consideration of reflection on action as a way in which professionals think critically about assumptions and processes of practice. Brookfield $(1995,2017)$ questions what it is to be critically reflective, and in so doing illuminates dynamics of power to 'hunt down' assumptions about practice, using four critically reflective lenses: autobiographic influences, colleagues' perceptions, learners' perceptions and theoretical insights to critically view teaching. Canning's (2011) study of pre-service vocational teachers at Stirling University contests the need for reflection of practice to prevail, considering instead that the pre-service teachers will benefit more from other discourses with peers and colleagues. However, even in this study, there is some acknowledgement that these other discourses would be opportunities for reflection in and on practice. Being reflective, however, is not a oneoff activity. Cowan and Stroud (2016) consider the need to not only think about 
reflecting in action, on action and for action, but to purposefully revisit previous reflections, turn them over, and allow growth, to enrich the reflective process and allow new perceptions to flourish. This recalls Moon's (2008) conceptualisation of ‘secondary reflection', undertaken via a double-entry reflective journal with adjoining left and right hand pages being using for primary and secondary reflections. The reflective process for professional learning and transforming practice is a purposeful, cyclical process that allows re-thinking and reshaping to take place.

In reviewing a decade of publications in Teacher and Teacher Education in relation to the professional development of teachers in schools, Avalos (2011) highlights the powerful impact on change in teachers' cognition, beliefs and practice. Her study showed that such changes can be gained through collaborative learning and reflective enquiry which is strengthened within formal courses where learning involves peer-coaching and collaborative projects, drawing on ideas about communities of practice discussed by Wenger et al. (2002). Drawing on Wenger's (1998) idea of a 'learning architecture,' the TQFE programmes offer participants varied forms of participation (modes of belonging) within a community of practice and support for learning as a process of identity change. The programmes encourage peer-learning and collaborative activity but perhaps without an emphasis on peer coaching, or the shared same goal for the collaboration that studies such as Dooner et al. (2008) highlight as being essential to learning communities. The TQFE course also reflects Wenger's subsequent work (2002) which focuses on the idea of a 'learning community' whereby '... a group of people act on an on-going basis to develop their knowledge of a common interest or passion by sharing individual resources and by engaging in critical dialogue' (as cited in Dooner, (2008). 
A key factor underpinning the development of 'critical dialogue' is that of trust and the TQFE course would appear to provide participants with a 'safe' but 'professional challenging' learning environment. Professional collaboration can take many forms which span a spectrum from the formal and pre-planned at one end to the non-formal and unanticipated at the other (Coffield 2000; Hodkinson and Hodkinson 2004). The potential value of 'practice artefacts' has been highlighted by a number of researchers but in particular Fischer (2001) who has noted that the sharing and discussion of 'practice artefacts' can offer opportunities for professional development and social creativity. On the TQFE programmes, collaboration is often enabled by the sharing and co-critique of learning artefacts. The varied forms of collaboration supported by the TQFE programmes have strong resonances with the idea of 'Joint Practice Development' as outlined by Fielding et al. $(2005,72)$ which '...underscores the necessity of mutual engagement.'

Bandura (1997) writes that teacher self-efficacy has a direct correlation with the effort they put into their jobs and this was borne out in the current study; believing in their own ability gives lecturers confidence and resilience. Callender and Little's (2015) study into the benefits for employees studying for a degree in HE highlighted the impact of increased self-confidence and self-belief, which allowed participants to feel better qualified and more confident in their work. Individuals in their study felt they had external credibility in the work as a result of gaining a degree, even if their job remained the same. In the current study, TQFE participants echo these findings. 
It is acknowledged that the economic factors in the UK impact on the funding available to the public sector. Lloyd and Payne $(2012,11)$ in a comparative study of Hairdressing lecturers' CPD found that where lecturers were looking to attend external pedagogic focused courses that they were generally not given financial support or 'relief from teaching' to do so . However, the considerations of professional learning must go beyond the financial considerations and as Lloyd and Payne (2012) highlight professional development is not 'just about going on courses'. It is the authors' view that broader considerations of the benefits of professional learning should also be given consideration such as the benefits highlighted by Mackay (2017): the psychological gains of building professional efficacy, enhancing resilience and supporting motivation to deepen professional knowledge.

Aside from the 2009 Scottish Government survey previously referenced, there has been little specific research into the impact of TQFE upon lecturer practice in Scotland to date. Husband (2015) considers this topic (in the Welsh context as well as Scottish) and concludes that in addition to finding programmes such as TQFE to be of benefit, offering an opportunity to learn academic skills and to forge useful working relationships with colleagues, there is a specific need for training in classroom management. In the view of the authors this latter point highlights a key tension between a competency based model of professional learning and a transformative one. The authors would seek a transformative model, to gain a broader perspective on professional practice, recognizing that the role of the lecturer in the 21 st century is highly complex and goes beyond the need for a classroom-based practice toolkit. 


\section{Methodology}

An initial pilot study, by online survey, was carried out in 2013. All participants who had completed the TQFE programme at any of the three institutions during the preceding year were sent an email, inviting them to complete the survey $(n=334)$. There was a very low response $(n=34$ i.e. $10.2 \%)$ to this survey and to a subsequent one, which surveyed associate staff who work in close partnership with the programmes, supporting TQFE participants in their places of work, despite each institution strongly encouraging participation by emailing their well-established TQFE networks at predetermined junctures. However, sufficient data was collected from these two surveys to suggest that a more in-depth approach, utilising individual interviews, would provide useful information about the impact of the TQFE upon current practice and for the future development of the programme in the three institutions. The early surveys further provided useful data for triangulation with the subsequent interview data.

The researchers undertook a thematic analysis - as usefully outlined by Braun and Clarke (2006) - of the interview data. This was 'contextualist' in approach, neither fully realist nor constructionist, but instead recognised that participants create meaning as individuals and social actors as well as agents within the specific reality of the contemporary college sector in Scotland.

\section{Insider researchers and the recruitment of research participants}

Purposive sampling was used to select the interviewees $(n=9)$, ensuring that there were representatives of each TQFE programme at undergraduate and post-graduate levels 
from each of the three universities, with mixed gender and length of experience in the Further Education sector. The research participants were chosen to represent a broad cross-section of the programme participants; they were from different cohorts and demographics of the programmes - pre-service and in-service, postgraduate and undergraduate, male and female.

Each researcher nominated for interviews three participants, one who had completed the programme in each of the following three sessions: 2012-13, 2013-14 and 2014-15. The researchers were aware of the potential difficulty of their status as 'insider' researchers. Whilst insider researchers may find it 'easier to gain access to research respondents and achieve deeper levels of trust, [their position] may also lead to assertions of bias and problems with the interview process' (Hanson 2013, 390). Insider researchers who are not vigilant about their status as such, run the risk of distorting data - focussing on items which fit with their own understanding of the context and influences explored in the study. Being well aware of such risks, the researchers mitigated against these where possible, for instance by only undertaking interviews with and subsequently focussing upon data from respondents who had not studied within their own institution.

\section{Method}

Having undertaken the relevant ethics procedures in the three different institutions, each researcher interviewed three respondents from one of the other institutions. The nine interviews were each recorded and transcribed by the respective interviewer. 


\section{Initial coding, leading to themes}

Firstly each interviewer reviewed the transcripts of the three interviews which they had undertaken themselves and one other set of interviews, also from an institution other than their own employer, creating a preliminary set of codes. Each of the three data sets (each comprising three interviews) was therefore reviewed and coded by two researchers, establishing inter-coder reliability. Thereafter the three researchers met to review together the codes and to collate these, going on to establish five themes from the initial collection of 21 codes as shown in Table 1.

Table 1. Initial codes

\begin{tabular}{|c|c|c|}
\hline & Preliminary codes & Established themes \\
\hline 1.1 & Confidence & (1) Perceived value of qualification \\
\hline 1.2 & Reassurance & \\
\hline 1.3 & Affirmation & \\
\hline 1.4 & Professional recognition & \\
\hline 1.5 & Identity capital & \\
\hline 2.1 & Professional update - need to be current & \\
\hline 2.2 & Professional values as an educator & $\begin{array}{l}\text { (2) Understanding of the role of the } \\
\text { lecturer in further education }\end{array}$ \\
\hline 2.3 & Learner differences & \\
\hline 2.4 & Adapting learning environments & \\
\hline 3.1 & Changing practice/adaptability & \\
\hline 3.2 & Connecting theory and practice & (3) Critical reflection on practice \\
\hline 3.3 & Engaging with literature & \\
\hline 4.1 & Sharing of practice/peer learning & \\
\hline
\end{tabular}




\begin{tabular}{|l|l|l|}
\hline 4.2 & Communities of practice & (4) Collaboration \\
\hline 4.3 & Cross-discipline awareness & \\
\hline 4.4 & Mentoring & \\
\hline 5.1 & Innovation and risk-taking & \multirow{2}{*}{ (5) Professional attributes } \\
\hline 5.2 & Knowledge and skills transferability & \\
\hline 5.3 & Research skills & \\
\hline 5.4 & Time management & \\
\hline 5.5 & Digital skills development & \\
\hline
\end{tabular}

Analysis using the five themes above is developed in the discussion which follows, leading onto the authors 'conclusions about the impact of TQFE on lecturer practice in Scotland today.

\section{Research findings and discussion}

\section{Theme 1: Perceived value of qualification}

This theme pertains to responses which focus on the impact of the TQFE programme on how interviewees think about themselves as professionals, how they relate to colleagues and their perceived status as education professionals. A number of interviewees commented on how the TQFE programme had enhanced their sense of themselves as education professionals (in addition to their previous professional identity) and how they felt more confident in contributing to debates about broad educational issues with other educators. 
There was a certain consciousness of feeling not only more like a professional with the TQFE achieved, but also becoming better able to do the job: 'it does give you that little bit more sort of a feeling of security and stability because you've got that qualification behind you, that backs up what you're saying in class' (Interviewee 3). Respondents spoke about the perceived low status of FE: 'FE is never considered to be particularly academic and that's always been a worry to me that I feel people don't realise what you have to do in order to do your job' (Interviewee 7) and how the qualification gave them confidence in their professional identity as FE lecturers: 'I think it helps you to be a bit more professional I would say, thinking a lot more professionally and now I feel that I am thinking about theory a lot more' (Interviewee 7). This is very much in keeping with Kennedy's (2005) transformative model. The importance of 'knowing that I've got that certificate in my head as well and obviously on the paper' (Interviewee 3) was remarked upon by various respondents - the certificate making a difference to their own sense of professional worth.

In addition to the qualification being perceived as giving status to the individuals, other perceptions around the value of the qualification related to the change of the interviewee's view about themselves as lecturers. Prior to undertaking the TQFE the lecturers may have undertaken a workplace professional development award (PDA) such as 'Assessor and Verifier' awards' as offered through the Scottish Qualifications Authority linked to the National Occupational Standards (SQA, undated). Such awards may focus on meeting quality assurance in workplace assessment and are different in purpose to the TQFE which seeks to support critiques of practice and ideas across a broad range of lecturer responsibilities. The TQFE seeks to build on previous 
professional learning through an emphasis on exploring a range of theoretical perspectives relevant to a broad range of practice. This focus on theoretical insight and a critical approach to practice was picked up in the interviews.

In all the interviews, respondents commented on their improved confidence, which would suggest that prior to undertaking the TQFE there was a lack in selfefficacy (Bandura 1997) - they were less sure of their practice as lecturers. The lecturers spoke of the reassurance they felt in learning about theory and discovering that their own practice was under-pinned by theoretical constructs: 'Yeah, because you're putting the theory into practice again, even though you've been doing the practical I felt as if we were getting more it was making more academic sense what we were doing so that was the reason I found it quite beneficial' (Interviewee 3). Having the qualification also lent a degree of professional recognition, allowing those qualified lecturers to support their colleagues: 'I think on a general day to day basis, having that qualification has given me an additional depth of understanding of academic areas... and certainly I've been able to support colleagues with issues that I've got some background knowledge as a result of the TQFE' (Interviewee 9).

The respondents all had professional identities in their own fields of work before taking up teaching often having been employed in a relevant industry sector (Husband, 2015). In becoming a lecturer in FE there is a need to add to this previous professional identity and the 'desire to make a difference' (that may have attracted them to becoming a lecturer) to being critically reflexive (Bathmaker and Avis, 2013). The respondents reported a professional identity as a lecturer as it was clear from the interviews that undertaking TQFE gave them a sense of professional value as lecturers, for instance in the following comment, made in the context of peer review of practice: 'having the 
confidence to actually say oh I liked what you did there but maybe you could do that, which I mean before my TQFE I wouldn't have even dreamed of saying that kind of thing' (Interviewee 8). How the lecturers are perceived by others, including their managers, also came over as important to the respondents: 'the immediate people two steps above you in management have got more confidence in you because you have been through [TQFE] ' (Interviewee 4). Whilst they may have secured a job as a lecturer because of their previous industry experience, the transformative nature of TQFE was evident in the increased capacity as professional educators rather than simply as classroom practitioners.

\section{Theme 2: Understanding of the role of lecturer in $\mathrm{FE}$}

This theme highlights how interviewees expressed a broadening sense of the role of the lecturer in FE, as set out in the Professional Standards (Scottish Government 2012). The theme pertains to interviewees describing a shift from seeing themselves as 'merely' classroom practitioners to having a wider role, both within and beyond the classroom, as demonstrated in Interviewee 8's remark '... things like even how the funding sort of side of things work I didn't know anything about that at all so it was quite interesting to see how that kind of impacted on sort of my day to day teaching life'. Interviewee 4 noted that TQFE has helped lecturers to pay attention to policy initiatives and changes which previously had not seemed relevant to their role. Further, there was a definite recognition of professional values associated with teaching and learning (as well as those to do with trades and subject specialisms). 
Interviewees remarked on how TQFE helped them to think of learners as individuals; Interviewee 5 for instance commenting: '... it's made me a lot more flexible... and able to deal with lots of different needs in the one room'. The environment in which learning happens was also much commented upon, with interviewees for instance noting the need to make appropriate adjustments to the environment in which learning and teaching happen. Interviewee 8 mentioned how (post TQFE) they now spend a few minutes before each class ensuring that the classroom furniture is arranged appropriately, for example to promote discussion, whilst Interviewee 6 tentatively noted that 'the TQFE in terms of my practice [is] probably made me look probably a bit more deeply at the environment'.

In terms of professional practice, it was not only the practical aspects of the TQFE programme which were foregrounded by the participants in interviews. Interviewee 1, for instance, commented, 'I reckon what you should do is re-do your TQFE, maybe every 10 years or, at the very least, read some books and do a couple of essays'. Whilst Interviewee 7 remarked, 'Well I think my writing skills are particularly good I think they were honed a lot by the TQFE... so it helped me to hone a bit more, and have more faith in my ability to write well... anyway I did feel that academically I felt a bit more able yeah I did feel a bit more able'. From these and other responses, it is clear that interviewees found the academic content of TQFE valuable to them as professional lecturers.

With the TQFE achieved, Interviewee 3 commented, 'I feel sort of comfortable to have ... discussions with people, professional discussions with people, now that I have that behind me' - pointing towards a shared set of values enabling professional-to- 
professional discussion, which was returned to in various interviews, pointing towards the collaborative, reflective practitioner, as described by Avalos (2011).

\section{Theme 3: Critical reflection on practice}

This theme relates to interviewees reflecting on experiences and their academic study to inform their practice. Interviewees offered exemplification of modifying their approaches in practice as a result of the TQFE experiences. They related these changes to making greater use of theory or adopting a more critical stance when thinking about their practice.

Critical reflection is a requirement of the Professional Standards for Lecturers in Scotland's Colleges which states 'Lecturers will also evaluate and reflect on the impact of their practice and their professional development on learning and on sustainable education' (Scottish Government 2012, 14). In the TQFE programmes offered by the three participating Universities there is a requirement to evidence critical reflection as part of professional practice and for this to be assessed within the assignment criteria for the courses - whether undertaken at an undergraduate level or postgraduate level of study. Therefore, it is unsurprising that the respondents exemplified ways in which their TQFE experiences led to changes in their practice driven by enhanced critical reflection.

Interviewees spoke of introducing concepts raised in the TQFE programme into their own class teaching, for example making use of learning communities in their own class. They also comment on changing their questioning, deepening their insight into 
students' learning and being 'more flexible' in how they teach. Interviewee 6 highlighted the developmental aspect of becoming more critical and the impact that this had on rethinking their learners' experiences: 'I did feel it did make me more reflective and due to the background knowledge I've gained from the TQFE I was then able to reflect on the academia and reflect on individuals and look at ways to improve myself and more so the experience of the learners' (Interviewee 6).

The responses from the interviewees again support the transformative nature of the TQFE in making connections between theory and practice, such as drawing on models of reflection to "hunt assumptions" (Brookfield 1995, 2017), to question that which is seemingly "common sense". For instance, interviewees talked about using research evidence to help them to look at practice in a completely different way, breaking down previous assumptions. The need to deconstruct what might seem obvious commonplace practice is one aspect of critical reflection as evidenced by Interviewee 9: 'General reflections on how I deliver my sessions the ability to critically reflect and refine my own practice was really useful and it gave me sort of skills with that as well. I think it really provided a kind of guidance to how to breakdown the whats and whys of my practice and of learning'. Interviewee 2 talked about the reshaping of practice with the learner at the centre: 'I'm asking them for their ideas, rather than us as a department, saying, "Well, we've researched this and this is how we're going to do it." It's bringing them very much into the decisions and sort of putting the learning in their court'. The engagement with research and academic literature brought a sense of deepening understanding and getting more academic sense and articulation as well as questioning of practice. 


\section{Theme 4: Collaboration}

This theme exemplifies ways in which the interviewees engaged in forms of peer learning to support either their practice or colleagues' practice, or engaged in mentoring of peers to support professional development, as a result of their TQFE experiences.

For many interviewees the TQFE programme enabled and supported varied forms of collaboration which were commented upon positively in a number of respects. A number of participants highlighted that the sharing of various 'teaching artefacts' (such as lesson-plans or assessment instruments) provided a very effective basis for professional collaboration as discussed by Fischer (2001). Some of these benefits appeared to be of particular relevance to Interviewee 8 who commented: 'sharing practice [...] it's made me more aware of being more analytical about my own teaching practice and also being able to, not necessary to support others because I don't know if I've been teaching long enough to do that [...] but being able to look at what they've done and think that works really well and I can see how that would work for my classroom or if I was doing it I could maybe tweak things about it and reuse a similar idea'.

Interviewees also commented clearly and frequently about the sense of developing a shared understanding within a community of practice as highlighted by Interviewee 2: 'speaking up within groups, but just I found it so good, the collaborative stuff that we did, knowing that you weren't alone and that other people are probably thinking the same as you.' One participant spoke of the ongoing support beyond the completion of the TQFE as the community continued their communications after the TQFE had ended. 
The notion of 'mutual engagement' (Fielding et al. 2005) can be seen in this response from Interviewee 5: 'but that was really good being able to look at other people's practice and learn from it and ask pertinent questions about other people's practice and being able to sort of collaborate with other people [...] you can develop your own better practice.' TQFE participants often report back through course evaluations that a key element in developing their learning were the opportunities for informal discussion and collaboration with colleagues from different disciplines and colleges. The interviewees reported that such interdisciplinary connections were usefully persisting well beyond the end of the programme, suggesting they become embedded in professional practice.

\section{Theme 5: Professional attributes}

This theme includes data pertaining to a range of aspects of practice in the FE sector, which interviewees had indicated contributed towards their sense of professionalism as lecturers. The interviewees spoke about making links between their practice and the literature they had been introduced to on the TQFE programme, about their increasingly positive attitude towards innovation in their classrooms and the importance of having a professional identity and updating skills.

The TQFE course is tightly aligned to the Professional Standards (Scottish Government 2012, 17) within which certain 'professional attributes' are clearly articulated, for instance: 'Lecturers must be flexible, reflective, innovative, creative and personally committed to continuing vocational and professional development'. 
Many participants mentioned innovation and risk taking and the support to do so offered by the TQFE but they were equally aware of the need to ensure that any such activity would have clear benefits for their leaners. In this respect they echoed the perspective offered by Hannan, English \& Silver (1999). The impetus to try something new and engage in some controlled risk-taking as part of the TQFE course was emphasised by Interviewee 8: 'I had my two observations and both times I tried to do something different that I'd never done before and do something innovative and different that I wasn't sure if it was going to work or not'. The potential of 'failed innovations' to be (possibly) effective vehicles for professional reflection and learning was emphasised by Interviewee 2: 'if they didn't work, it wasn't a bad thing, you just learned from it and adapted that or tried something different and just not being afraid to try things differently and look back on what benefit or not they were to your lesson or to your learners'.

The notion of controlled experimentation and rigorous analysis of the processes and outcomes of innovative teaching practice were highlighted by Interviewee 6: 'I was able to take more calculated risks and constantly change as I was actually delivering it was quite an interactive lesson and I could almost sense where things weren't being picked up and I was actually changing a lot of it as I went along and added more new things... [TQFE] did give you a more in-depth look at how you actually deliver learning'. 


\section{Conclusion}

This study sought to explore the perceptions of TQFE as a transformative learning experience for lecturers in Scotland's college sector. The evidence drawn from the three institutions providing TQFE demonstrates that the programmes do offer a transformative model of professional development. Further, the authors would argue that such a transformative model is essential in helping practitioners to develop as education professionals with the wide perspective on professional practice which is required in today's complex education context. Given the multi-faceted nature of the role of the modern college lecturer, learning about classroom techniques alone is insufficient. The constant evolution of the education landscape requires practitioners who are open to innovation and change in their practice. They must be open to the complexities of learning and able to challenge received wisdom and have the capacity to make well-informed professional judgements. TQFE affords participants confidence in academic literacies. The lecturers interviewed for this study do apply research evidence to their practice, benefitting from being part of a learning community which takes a critical stance towards practice through collaborative approaches. Undertaking TQFE enables participants to adopt a new professional identity as educators and within that identity deal effectively with other professionals.

The value of ongoing critically informed practice is highlighted by the Professional Update process mandated by the General Teaching Council for Scotland (2012) for ongoing professional registration for teachers in Scotland (TQFE enables lecturers in Scotland to register with the GTCS). The Professional Standards developed by the Education and Training Foundation (Education \& Training Foundation 2014) requires FE practitioners to "Develop deep and critically informed knowledge and 
understanding in theory and practice". Similarly the Higher Education Academy's (2011) UK Professional Standards Framework promotes CPD underpinned by evidenceinformed approaches as does the 'CLD Standards Council Scotland' through its 'Professional Development Strategy' (CLD Standards Council Scotland, 2015). As the Professional Standards for Lecturers in Scotland's Colleges are about to be reviewed, coordinated by the College Development Network, it is essential that the new standards are underpinned by a transformative model of professional development, with practitioner enquiry at the core. College lecturers can find themselves having to meet each of these sets of standards and thus it is imperative that their new standards can readily articulate with the others. Furthermore, the complexities of multiple overlapping standards must also be reflected in TQFE programmes and their emphasis on transformative professional learning and development.

The fast-changing environment which characterises the colleges sector in Scotland requires lecturers to be highly effective across a range of professional activities, particularly when there is less time and fewer resources available. One consequence of less time being available is that many TQFE participants are now completing the course in their own time with no or very limited remission from their teaching. The TQFE programme experiences must therefore ensure that the professional learning offered provides challenging opportunities within supportive collaborative communities: a model which can be sustained beyond TQFE. This study demonstrates that TQFE is valued by course participants and influences their professional practices in important ways. 


\section{Limitations of the study}

This is a small scale study involving qualitative data from three institutions in Scotland and thus findings may not have wider applicability.

\section{Possible future work}

Further studies across a range of educational contexts examining the challenges and opportunities afforded by transformative professional development are required in order to evidence the impact on learning. The concept of practitioner enquiry (as advocated by professional bodies and more widely) could pave the way for rigorous studies of the impact across a variety of educational settings. There is also a need for a synthesis of findings from small-scale studies to identify wider impact on systemic change in education.

\section{Acknowledgements}

The authors would like to thank the participants of the study for the insight that was added through their engagement with the surveys and the interviews. Particular thanks go to Sarah Cornelius of the University of Aberdeen for her contribution to the design and analysis of the surveys at the initial stages of the study. 


\section{References}

Avalos, B. 2011. "Teacher professional development in Teaching and Teacher Education over ten years." Teaching and Teacher Education 2011 (27):10-20. doi: http://doi.org/10.1016/j.tate.2010.08.007.

Bandura, A. 1997. Self-efficacy: The exercise of control. New York: W. H. Freeman. Bathmaker, A-M, and J. Avis. 2013. "Inbound, outbound or peripheral: the impact of discourses of 'organisational' professionalism on becoming a teacher in English further education." Discourse: Studies in the Cultural Politics of Education 34 (5):731-48. doi: 10.1080/01596306.2013.728367.

Beauchamp, G., L. Clarke, M. Hulme, M. Jephcote, A. Kennedy, G. Magennis, I. Menter, et al. 2016. Teacher education in times of change. Bristol: Policy Press.

Braun, V., and V. Clarke. 2006. "Using thematic analysis in psychology." Qualitative Research in Psychology 3 (2):77-101. doi: http://dx.doi.org/10.1191/1478088706qp063oa.

Brookfield, S. 1995. Becoming a critically reflective teacher. San Francisco, CA: Jossey-Bass.

Brookfield, S. 2017. Becoming a critically reflective teacher. 2nd ed. San Francisco, CA: Jossey-Bass.

Callender, C., and B. Little. 2015. "The hidden benefits of part-time higher education study to working practices: is there a case for making them more visible?" Journal of Education and Work 28 (3):250-72. doi: http://dx.doi.org/10.1080/13639080.2014.894635.

Canning, R. 2011. "Reflecting on the reflective practitioner: vocational initial teacher education in Scotland." Journal of Vocational Education \& Training 63 (4):609-17. doi: http://dx.doi.org/10.1080/13636820.2011.560391.

CLD Standards Council Scotland. 2015. Growing the Learning Culture in CLD: A Strategy Statement and Framework for Action. Glasgow: CLD Standards Council Scotland. Accessed 4 May 2017. http://cldstandardscouncil.org.uk/?page_id=297.

Coffield, F. 2000. The necessity of informal learning. Edited by Economic and Social Research Council (Great Britain), The learning society. Bristol: Policy Press.

Cowan, J., and R. Stroud. 2016. "Composting reflections for development." Reflective Practice 17 (1):27-33. doi: http://dx.doi.org/10.1080/14623943.2015.1123684. 
Dewey, J. 1910. How we think. Boston [Mass.]: Heath.

Dooner, A., D. Mandzuk, and R. A. Clifton. 2008. "Stages of collaboration and the realities of professional learning communities." Teaching and Teacher Education 24 (3):564-74. doi: http://doi.org/10.1016/j.tate.2007.09.009.

Education \& Training Foundation. 2014. Professional Standards for Teachers and Trainers in education and Training. London: Education \& Training Foundation.

Fielding, M., S. Bragg, J. Craig, I. Cunningham, M. Eraut, S. Gillinson, M. Horne, C. Robinson, and J. Thorp. 2005. "Factors Influencing the Transfer of Good Practice." In.: University of Sussex / Demos.

Fischer, G. 2001. "External and shareable artifacts as opportunities for social creativity in communities of interest." In Computational and Cognitive Models of Creative Design. Key Centre of Design Computing and Cognition, University of Sydney, Heron Island, Australia.

Hannan, A., S. English, and H. Silver. 1999. "Why innovate? Some preliminary findings from a research project on 'innovations in teaching and learning in higher education'." Studies in Higher Education 24 (3):279-89. doi: http://dx.doi.org/10.1080/03075079912331379895.

Hanson, J. 2013. "Educational developers as researchers: the contribution of insider research to enhancing understanding of role, identity and practice." Innovations in Education and Teaching International 50 (4):388-98. doi: http://dx.doi.org/10.1080/14703297.2013.806220

Higher Education Academy 2011. "UK Professional Standards Framework (UKPSF)." Accessed 4 May 2017. https://www.heacademy.ac.uk/recognition-accreditation/ukprofessional-standards-framework-ukpsf.

Hodkinson, P., and H. Hodkinson. 2004. "The complexities of workplace learning." In Workplace learning in context, edited by Helen Rainbird, Alison Fuller and Anne Munro, 259-76. London: Routledge.

Husband, G. 2015. "The impact of lecturers' initial teacher training on continuing professional development needs for teaching and learning in post-compulsory education." Research in Post-Compulsory Education 20 (2):227-44. doi: http://dx.doi.org/10.1080/13596748.2015.1030262. 
Kennedy, A. 2005. "Models of Continuing Professional Development (CPD): A framework for analysis." Journal of In-service Education 31 (2):235-50. doi: http://dx.doi.org/10.1080/13674580500200277.

Lloyd, C., and J. Payne. 2012. "Raising the quality of vocational teachers: continuing professional development in England, Wales and Norway." Research Papers in Education 27 (1):1-18. doi: http://dx.doi.org/10.1080/02671522.2010.483524.

Menter, I., M. Hulme, D. Elliot, and J. Lewin. 2010. Literature Review on Teacher Education in the 21st Century.

Moon, J. 2008. Critical Thinking: An Exploration of Theory and Practice. Abingdon: Routledge.

Rainbird, H., A. Fuller, and A. Munro. 2004. Workplace learning in context. London: Routledge.

Schön, D. A. 1983. The reflective practitioner : how professionals think in action. New York, NY: Basic Books.

Scottish Executive. 2006. Professional Standards for lecturers in Scotland's Colleges. Edinburgh: Scottish Executive.

Scottish Government. 2010. The Teaching Qualification (Further Education) Candidate Satisfaction Survey 2009: Report of Findings. Edinburgh: Scottish Government.

Scottish Government. 2012. Professional Standards for Lecturers in Scotland's Colleges. Edinburgh: Scottish Government.

Scottish Government. 2016. Professional Standards for Lecturers in Scotland's Colleges. Edinburgh: Scottish Government.

SQA (Scottish Qualifications Authority) 2017. "Qualifications for Assessors and Verifiers." Accessed 4 May 2017. http://www.sqa.org.uk/sqa/48368.html.

Tripp, D. 1993. Critical Incidents in Teaching. New York: RoutledgeFalmer.

Wenger, E. 1998. Communities of practice: Learning, Meaning, and Identity, Learning in doing: social, cognitive, and computational perspectives. Cambridge: Cambridge University Press.

Wenger, E., R.A. McDermott, and W. Snyder. 2002. Cultivating communities of practice : a guide to managing knowledge. Boston, MA: Harvard Business School Press. 